\title{
Thermal footprint effect of rooftop urban cooling strategies
}

By Dylan Botham-Myint, Gerald W. Recktenwald, and David J. Sailor ${ }^{*}$

Mechanical and Materials Engineering

Portland State University, Portland OR, USA

\begin{abstract}
Simulation results indicate that urban morphology plays an important role in determining the efficacy of rooftop urban cooling strategies for improving pedestrian thermal comfort. Results suggest that a white roof has the greatest effect on near-surface air temperatures within the urban canyon when used on buildings of 1-2 stories height and almost no near-surface effect when applied to 4 story buildings. However, the near-surface effect is more substantial when complex urban morphology introduces enhanced vertical mixing. Of the cases studied the largest near-surface cooling benefit of implementing white roofs was found for the case when a taller building existed downwind from a building with a white roof. Using the Thermal Footprint Ratio it was found that by placing a tall building behind a building with a white roof in an otherwise uniform array of 2 story buildings, the cool roof would be twice as effective at reducing air temperatures at the pedestrian level. Calculations of the volumetric heat removal confirmed this result, indicating that the positioning of the tall building downwind of the modified roof would be 2.6 times as effective at cooling the pedestrian level air volume as compared to the case where all buildings were a uniform height.
\end{abstract}

Keywords: urban heat islands; urban climate; cool roofs; heat island mitigation; building heights

* Corresponding author: sailor@pdx.edu 


\title{
Introduction
}

As of 2011 , approximately $52 \%$ of world population lives in areas classified as urban with a projected rise to $67 \%$ by 2050 [1]. This rapid urbanization has led to environmental concerns due to increased $\mathrm{CO}_{2}$ emissions, high rates of energy consumption, habitat loss, and local climatic changes due to land-use modifications [2] [3] [4]. Land surface modification and human activities have led to a warming effect whereby the air and surface temperatures within the urban environment often exceed those in rural and suburban areas. This "urban heat island" (UHI) effect is due to many factors including the greater thermal mass for urban spaces, lower surface albedo, high prevalence of impervious surfaces, complex urban morphology that restricts radiation exchange and air flow, and a higher rate of anthropogenic heat emissions. The UHI has been shown to increase summertime cooling loads for cities in warm and hot climates, contribute to urban air pollution by accelerating smog formation, and exacerbate heat stress, adversely affecting human health during extreme weather events [5] [6] [7] [8].

There has been much prior study of the causes and effects of the urban heat island as well as mitigation of its adverse effects. Grimmond has compiled a concise overview of the various complex causes of the urban heat island along with examples of some proposed mitigation strategies [9]. Urban heat island (UHI) mitigation strategies are divided into three categories: (1) increasing surface albedo, (2) increasing evaporative cooling (generally by increasing vegetation cover), and (3) reduction of anthropogenic waste heat [7] [10] [11].

\begin{abstract}
Albedo strategies focus on increasing the reflection of incoming short-wave solar radiation by highly reflective (high albedo) surfaces—often referred to as "cool" or "white" surfaces. This increase in reflected solar energy has several direct and indirect effects. First, it results in a direct cooling of the surface itself. For example, in a study of buildings in six California cities, Akbari and colleagues found that cool roofs had the potential to reduce daily peak roof temperatures by 33 to $42{ }^{\circ} \mathrm{C}$ [12]. In
\end{abstract}



found that the surface temperature of a concrete roof was about $10^{\circ} \mathrm{C}$ greater than that of a white membrane roof during August. In Poitiers France, a cool roof on a four-story duplex was monitored and found to reduce mean roof surface temperature by more than $10^{\circ} \mathrm{C}$ relative to an asphalt roof [14].

The surface cooling associated with use of highly reflective roofing results in reduced heat conduction into buildings as well as reduction in ambient air temperatures that translates into less heat penetration into buildings through ventilation and infiltration. These effects combine to reduce the demand for air conditioning and also improve indoor thermal comfort for unconditioned buildings [15] [16] [17]. For example, using the TRNSYS building thermal simulation software [18], Synnefa et al. found that cool roofing could reduce annual and peak cooling loads by $18-93 \%$ and $11-27 \%$, respectively. They also noted that, for unconditioned buildings, the addition of cool roofs significantly improved indoor thermal comfort conditions, with a decrease of hours outside of ASHRAE comfort guidelines by $9-100 \%$ [19].

Previous studies have also used numerical simulations to understand the regional cooling effect that albedo increases would have on the local urban climate. Through a mesoscale simulation, Sailor [20] found that a moderate regional albedo increase of 0.14 could reduce peak summer air temperatures in Los Angeles by $1.5^{\circ} \mathrm{C}$. Krayenhoff and Voogt [21] used a 1-D boundary layer mixing model to show that roof albedo increases of $0.19,0.26$, and 0.59 resulted in summertime maximum air temperature reductions of $1.1,1.5$, and $3.6{ }^{\circ} \mathrm{C}$ in two neighborhoods in Chicago. Further mesoscale modelling by Synnefa et al. [22] using the MM5 mesoscale atmospheric model found that extreme increases to rooftop albedo from 0.18 to 0.85 could reduce the urban heat island by $1-2{ }^{\circ} \mathrm{C}$ at $2 \mathrm{~m}$ in Athens, Greece.

As a result of the growing literature of modeling studies of urban heat mitigation it has become generally accepted that high albedo strategies have the potential to cool cities by 1 to $3{ }^{\circ} \mathrm{C}$. These studies, however, generally rely on mesoscale modelling techniques where near-surface transport 
effects are parameterized. Models such as these typically ignore or poorly represent the complexity of mixing processes within the urban canyon caused by localized flow interactions. In addition, building height may play a significant role in any roof modification scenario aiming to reduce near-surface temperatures. Microscale numerical modeling techniques have also been used to study surface albedo modification - many performed through use of ENVI-met [23]. Emanuel and Fernando [24], for example, showed that a high albedo scenario in downtown Phoenix, Arizona produced somewhat lower daytime air temperature but higher nighttime temperatures. In a similar study using ENVI-met, Emmanuel et al. [25] found that albedo modification at the street level in Colombo, Sri Lanka successfully reduced daytime air temperature by $1{ }^{\circ} \mathrm{C}$. This study pointed out, however, that the urban aspect ratio had a much greater effect on thermal comfort in terms of physiological equivalent temperature (PET), than did urban albedo. Saneinnejad et al [26] simulated an urban street canyon using a Computational Fluid Dynamics (CFD) model to compare several proposed urban heat mitigation strategies and found that albedo increases resulted in maximum cooling effect of $4.3^{\circ} \mathrm{C}$ for a typical scenario or $6{ }^{\circ} \mathrm{C}$ during a heat wave.

Possible unintended consequences of an increase in white roofs have been suggested by several authors. Georgescu et al., [27] found that the use of highly reflective surfaces within the Phoenix AZ metropolitan area may have an impact on the hydrologic cycle by further reducing evapotranspiration. Using the Weather Research and Forecasting model (WRF), several scenarios were simulated and a 4\% accumulated precipitation decrease was found for the case of maximum expansion without surface modifications. Yang et al., [28] compiled a sizeable number of unintended consequences resulting from the use of reflective surfaces, including roof condensation leading to mold and deterioration, snow and ice buildup resulting in an increased use of deicing salts and chemicals, increased building heating cost during winter, radiation reflected onto other neighboring buildings and surfaces, light pollution, and health risks from increased ultra-violet radiation exposure. 
Despite the growing interest in, and widespread study of high albedo surfaces for UHI mitigation, most researchers have paid little attention to the role that building morphology may play in the efficacy of mitigation strategies. The primary mechanisms for cooling the city are by convection heat transfer at the level of the roof and vertical mixing of air between the street and roof levels. Thus, it is reasonable to hypothesize that the efficacy of rooftop heat island mitigation strategies will depend greatly on both the height of the roofs being modified and the morphology of the surrounding neighborhoods. This paper addresses this hypothesis through a detailed CFD analysis of rooftop heat island mitigation.

\section{Methods}

\section{Model Configuration}

All simulations in this study were performed using the computational fluid dynamics program STAR $\mathrm{CCM}+$ version 9. This application employed the non-hydrostatic Boussinesq-approximated Reynoldsaveraged Navier-Stokes equations (RANS), using a standard $k-\varepsilon$ turbulence closure model and the classic wall-function approach. Steady state solutions to the governing discretized equations are found using the finite volume method. A segregated solution method based on the SIMPLE algorithm is used to resolve the pressure-velocity coupling [29]. Diffuse long-wave radiation was simulated with a graythermal surfaces model that assumes all surfaces exchange wavelength-independent radiation with no participating bulk media. The surface energy balance was represented simply by specifying surface temperature boundary conditions consistent with case study observational data for the various surfaces involved in the study. This representation clearly has limitations but was chosen as a simplification along with a steady state approximation so the study could isolate the fundamental characteristics of the heat transfer in complex urban geometries.

As illustrated in Figure 1, the modeling domain represents a 5 by 5 array of buildings in which all buildings initially have the same rooftop surface albedo. A high albedo test case then replaces the roof 


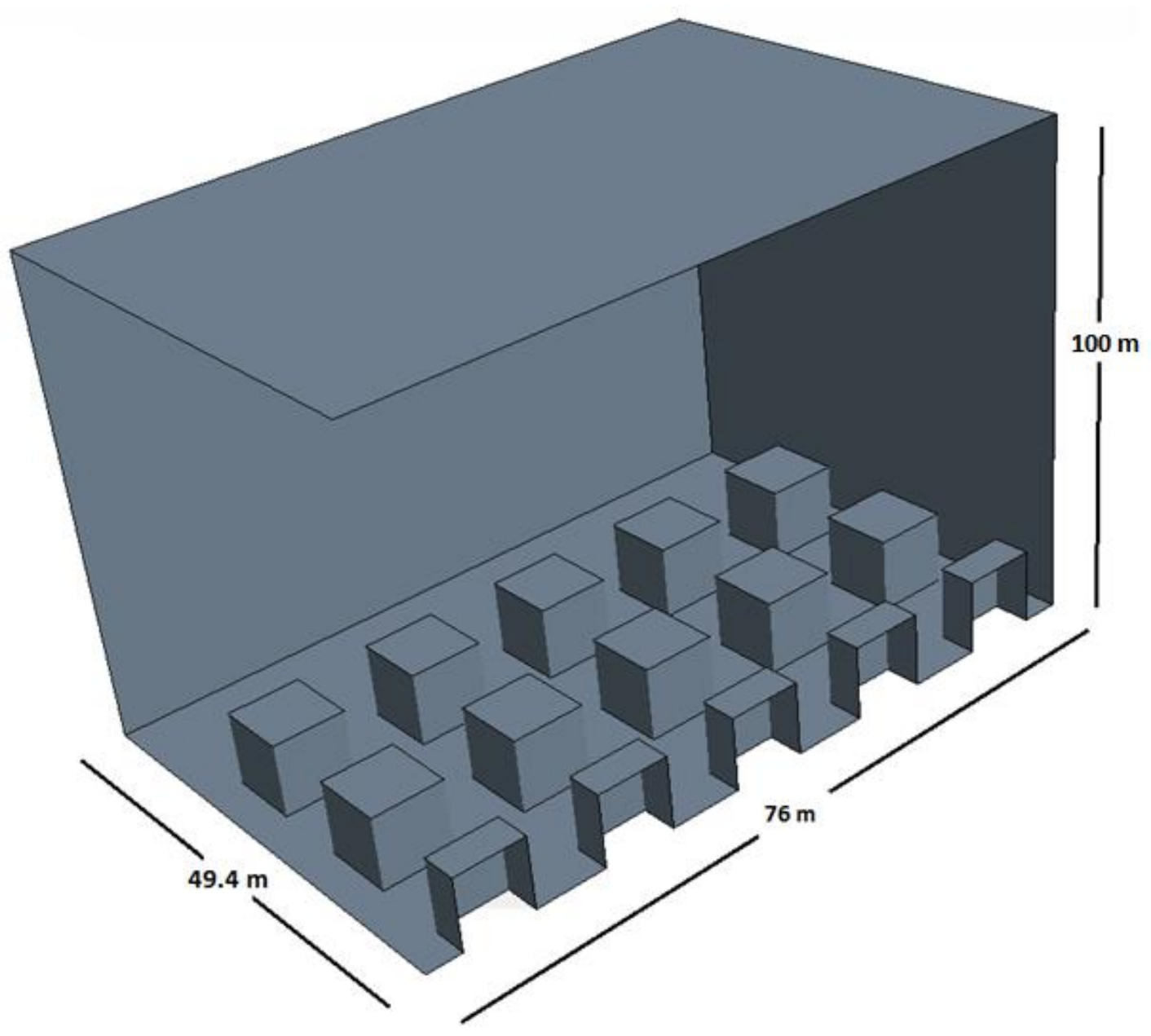

Figure 1: CFD domain of air volume representing the 5 by 5 grid of buildings, utilizing symmetry down the middle of the domain.

An initial model with periodic boundary conditions was used to generate inlet profiles for velocity and turbulence quantities. Model simulations then used this inlet condition with an array of repeated blackroofed buildings and a specified stream-wise pressure drop of $1.0 \mathrm{~Pa}($ or $0.013 \mathrm{~Pa} / \mathrm{m}$ ) between the two boundaries as shown in Figure 2. Top and Lateral flow boundaries were slip conditions while building and road surfaces were simple no slip conditions. A symmetry condition parallel to the flow direction was applied to reduce computation time. 
The outflow boundary was a flow split condition that forces mass conservation at the boundary and an outlet pressure that is extrapolated from adjacent cells using reconstruction gradients computed from a hybrid Gauss/weighted least-squares method for all variables. To avoid instances of backflow recirculating into the domain, a mesh "extruder" was used to increase the runoff distance at the outflow of the model from $76 \mathrm{~m}$ to $106 \mathrm{~m}$ by including orthogonal cells at the outflow boundary surface, effectively adding $30 \mathrm{~m}$ downstream of the domain.

Boundary conditions used to solve the energy equation were fixed temperatures (see Table 1). These temperatures were chosen to abstract the thermal conditions that may be present for a typical midlatitude North American city on a hot summer afternoon. They were based on measurements taken using an infrared camera during a helicopter traverse through Portland Oregon on August 22, 2011.

Table 1. Surface temperature boundary conditions for each surface in the CFD models.

\begin{tabular}{lc}
\hline Boundary & Temp. $\left({ }^{\circ} \mathrm{C}\right)$ \\
\hline Road & 40 \\
Walls & 30 \\
Black Roof & 55 \\
White Roof & 35 \\
Air (entry) & 30 \\
\hline
\end{tabular}

The majority of the domain was meshed with a polyhedral mesh of a nominal base size of $1.2 \mathrm{~m}$. A prismlayer mesh of an approximate thickness of $1 \mathrm{~m}$ was used to transition the grid size near all surfaces. Contained within this layer was between 4-12 nodes depending on the $y+$ (dimensionless wall coordinate) values calculated along each surface. Because the simulation used a high $y+$ wall treatment model, it is recommended that the centroid of each wall-cell remain within the logarithmic layer. This translates to $y+>30$ at all surfaces and is the driving factor for determining the number and size of nodes within each surface's prism layer. A further constraint was that $y+$ values should not exceed 500 
to maintain accuracy [33]. Most of the simulations in this study were actually performed with surface $y+$ values of 30-300, remaining well within the mentioned limits. Each simulation case included approximately $3 \times 10^{5}$ simulated grid volumes and required roughly 30 hours of computation time on a high-end desktop workstation.
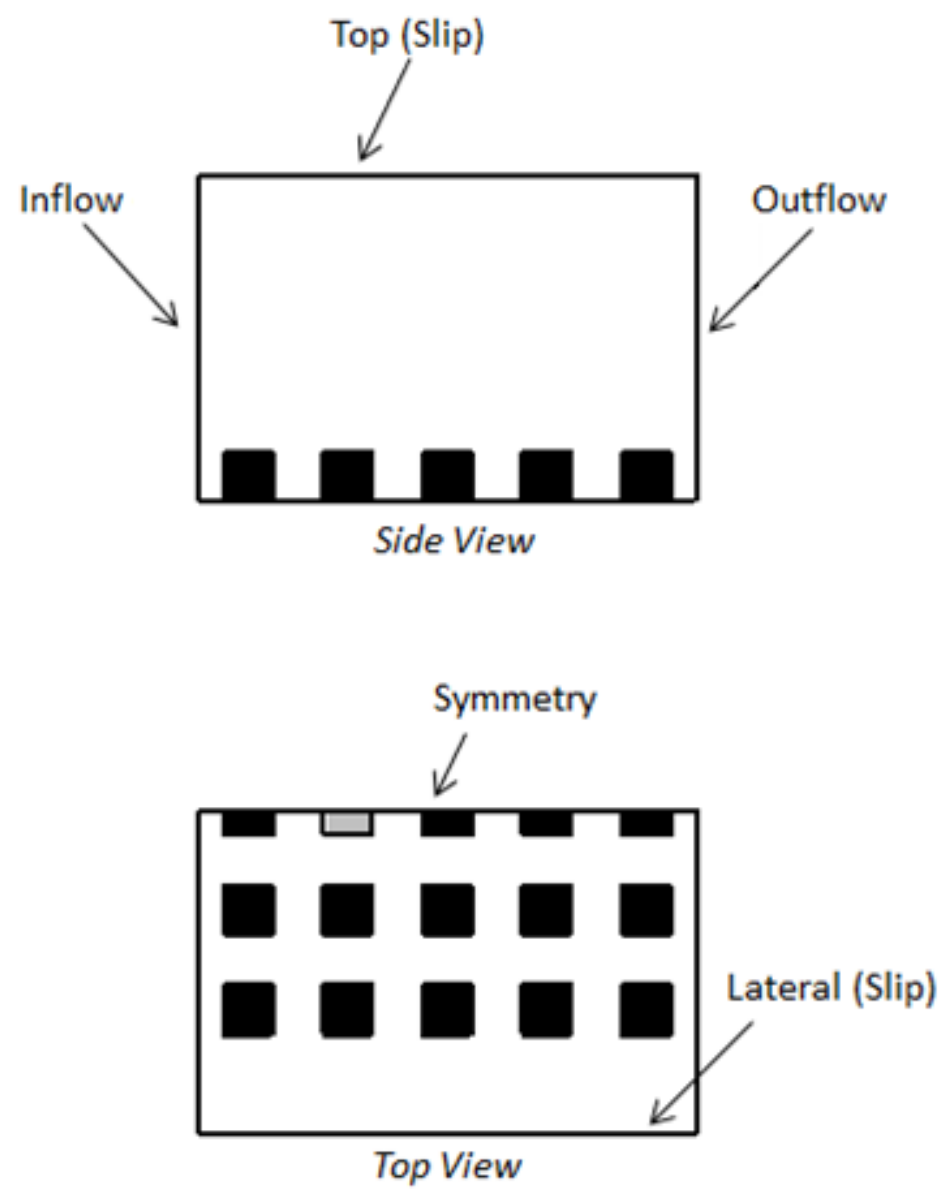

Figure 2: Domain and boundary conditions for solving the momentum equations (white roof shown in grey). 
Five cases of differing canyon geometry were modeled, as illustrated in Figure 3. All buildings in Case 1 and 2 were uniform height at 2 and 4 stories, respectively (e.g., 1:1 and 2:1 height to width ratios). Cases 3 and 4 each have a single 4 story building amidst an array of 2 story buildings, and Case 5 has an array of uniform 1 story buildings. Each case was run with all roof surfaces black as a control case. Then a test case was simulated in which the roof of a single building in the center of the second row was changed to white (indicated in Figure 3 by the lighter shaded building).

\section{Measuring the "thermal footprint"}

The temperature perturbation, or "thermal footprint" caused by the introduction of the white roof is measured using several methods. The Thermal Footprint Ratio $\left(\mathrm{TFR}_{h}\right)$ at a given cross-sectional height 
(h) is a new metric defined as the ratio of area significantly mitigated $\left(A_{\text {mit }}\right)$ by the roof modification to the area of the modification $\left(A_{\text {mod }}\right)$.

$$
\operatorname{TFR}_{h}=\left.\frac{A_{\text {mit }}}{A_{\text {mod }}}\right|_{h}
$$

Here, "significantly mitigated" is defined as any model grid cell for which the introduction of the white roof resulted in more than a $0.1^{\circ} \mathrm{C}$ change in air temperature from the control scenario. The area of modification is simply the area of the roof that is modified. In these simulations it is assumed that the entire surface of the roof can be modified. The TFR $\mathrm{h}$ can be evaluated at any desired height, and is illustrated qualitatively in Figure 4 for the pedestrian height of $h=2 m$.

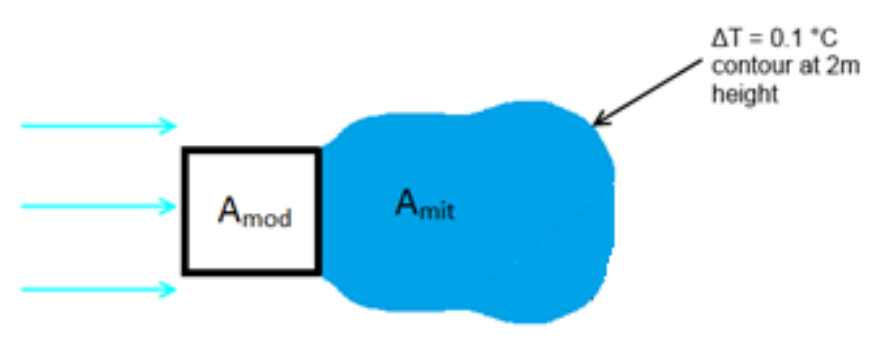

Figure 4: Example of the "Thermal Footprint" effect of modifying a single building roof.

If the interest of a certain UHI mitigation strategy is in assessing the total air volume significantly affected by the strategy, one might integrate the thermal footprint over the height of the domain. Taking this idea further, we introduce the concept of the Volumetric Heat Removal (VHR):

$$
V H R=\int \rho c_{p}\left[T_{\text {mod }}-T_{c n t r l}\right] d V
$$

Where $\rho$ is air density, $c_{p}$ is the specific heat of air, $T_{\bmod }$ is the local air temperature in the modification scenario, $T_{\text {cntrl }}$ is the air temperature in the control scenario, and the integration takes place over the volume of airspace of interest (e.g. for the entire simulation domain, or simply for the air volume up to the $2 \mathrm{~m}$ height). For the case of a high albedo modification the VHR will be a negative number, 
representing an overall cooling of the airspace. In the context of a CFD simulation, the VHR is essentially a sum over all grid volumes of the temperature difference between the grid volume for the modification and control cases multiplied by the grid volume and volumetric specific heat.

\section{Results}

Contour plots of air temperature reductions $\left(T_{\text {mod }}-T_{\text {cntrl }}\right)$ for each of the 5 cases are shown in Figures 5-9 and show temperature changes at the $2 \mathrm{~m}$ height (top views) as well as vertically through the domain at the location of the symmetry boundary (side views). Table 2 summarizes both the volumetric heat removal (VHR) and the thermal footprint ratio $\left(\mathrm{TFR}_{2 m}\right)$ metrics for evaluating urban cooling strategies. Volumetric heat removal has been evaluated at both the domain scale and for the pedestrian scale $(2 \mathrm{~m}$ volume of air at ground surface) while the thermal footprint ratio is evaluated at $2 \mathrm{~m}$ height for several temperature thresholds.

Table 2. Total volumetric heat removal values (negative values indicate heat removal) for two volume scales and thermal footprint ratio for differing threshold values of temperature difference.

\begin{tabular}{ccccccc}
\hline \multicolumn{3}{c}{ Volumetric Heat Removal (VHR) } \\
\hline & $\begin{array}{c}\text { Domain } \\
\text { Case }\end{array}$ & $\begin{array}{c}\text { Pedestrian } \\
(\mathrm{kJ})\end{array}$ & $\begin{array}{c}0.10{ }^{\circ} \mathrm{C} \\
(-)\end{array}$ & $\begin{array}{c}0.15{ }^{\circ} \mathrm{C} \\
(-)\end{array}$ & $\begin{array}{c}0.20{ }^{\circ} \mathrm{C} \\
(-)\end{array}$ & $\begin{array}{c}0.25{ }^{\circ} \mathrm{C} \\
(-)\end{array}$ \\
\hline 1 & -672.2 & -78.8 & 0.5 & 0.1 & 0 & 0 \\
2 & -1167.1 & -76.3 & 0 & 0 & 0 & 0 \\
3 & -993.5 & -208.1 & 1.0 & 0.3 & 0 & 0 \\
4 & -493.7 & -1.2 & 0 & 0 & 0 & 0 \\
5 & -583.6 & -84.9 & 0.8 & 0.5 & 0.4 & 0.1 \\
\hline
\end{tabular}



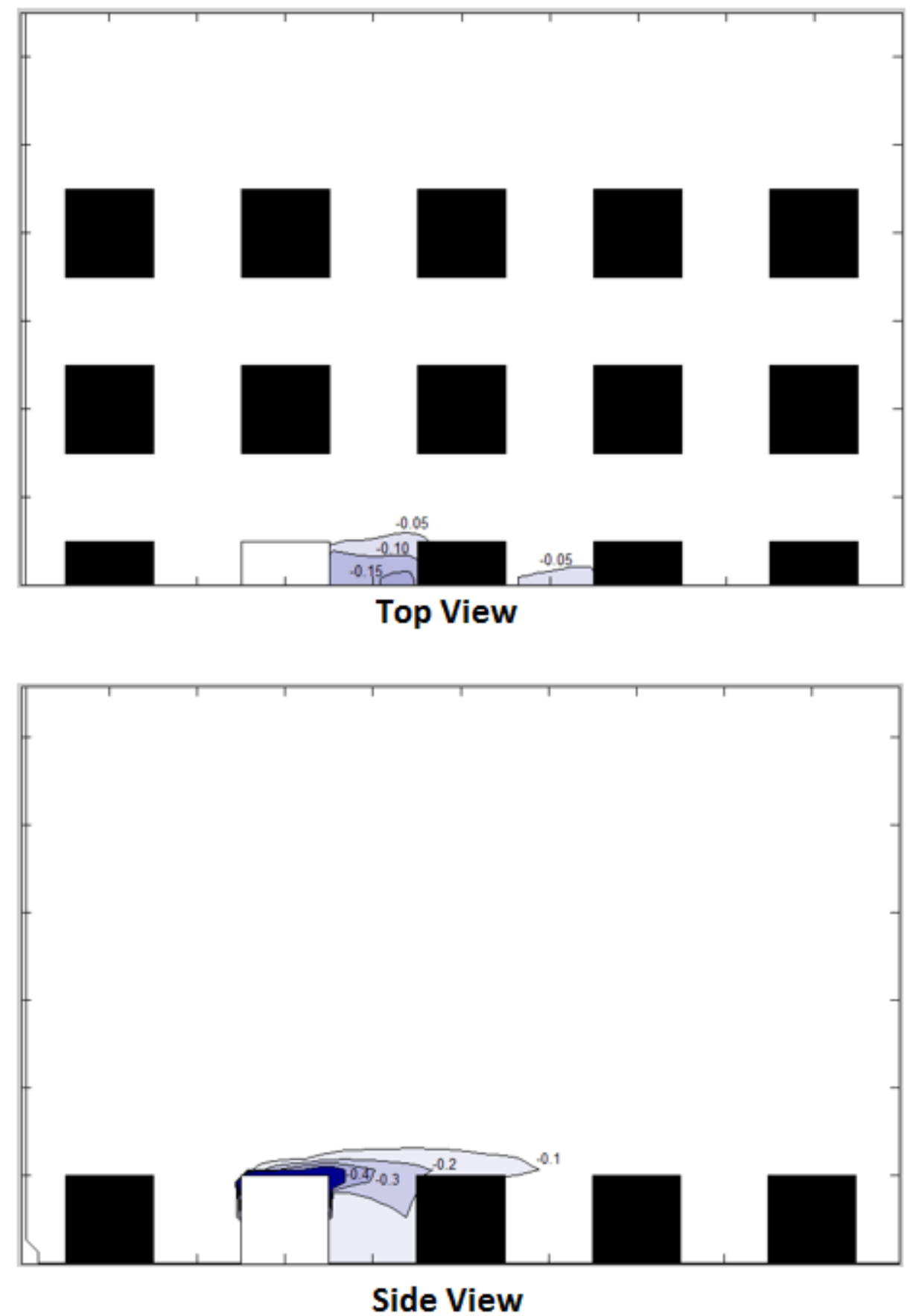

Figure 5: Temperature reductions $\left({ }^{\circ} \mathrm{C}\right)$ for Case $1(\mathrm{H} / \mathrm{W}=1: 1)$ single white roof (height 7.6 meters) within array of buildings with uniform height 7.6 meters 
Figure 6: Temperature reductions $\left({ }^{\circ} \mathrm{C}\right)$ for Case $2(\mathrm{H} / \mathrm{W}=2: 1)$ single white roof (height 15.2 meters) within array of buildings with uniform height 15.2 meters 
Figure 7: Temperature reductions $\left({ }^{\circ} \mathrm{C}\right)$ for Case 3 single white roof (height 7.6 meters) within array of buildings with uniform height 7.6 meters except for a single tall building of height 15.2 meters downwind.

\section{Top View}

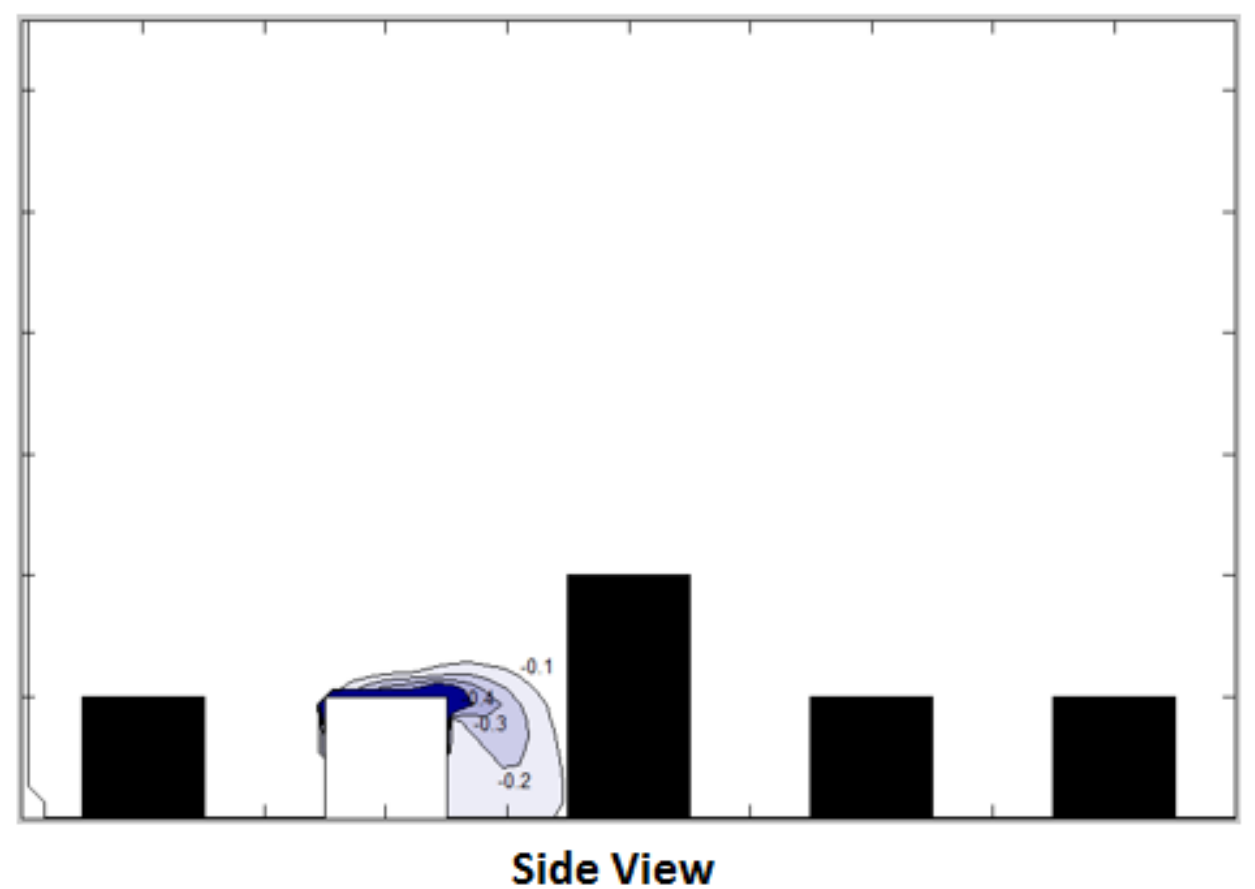




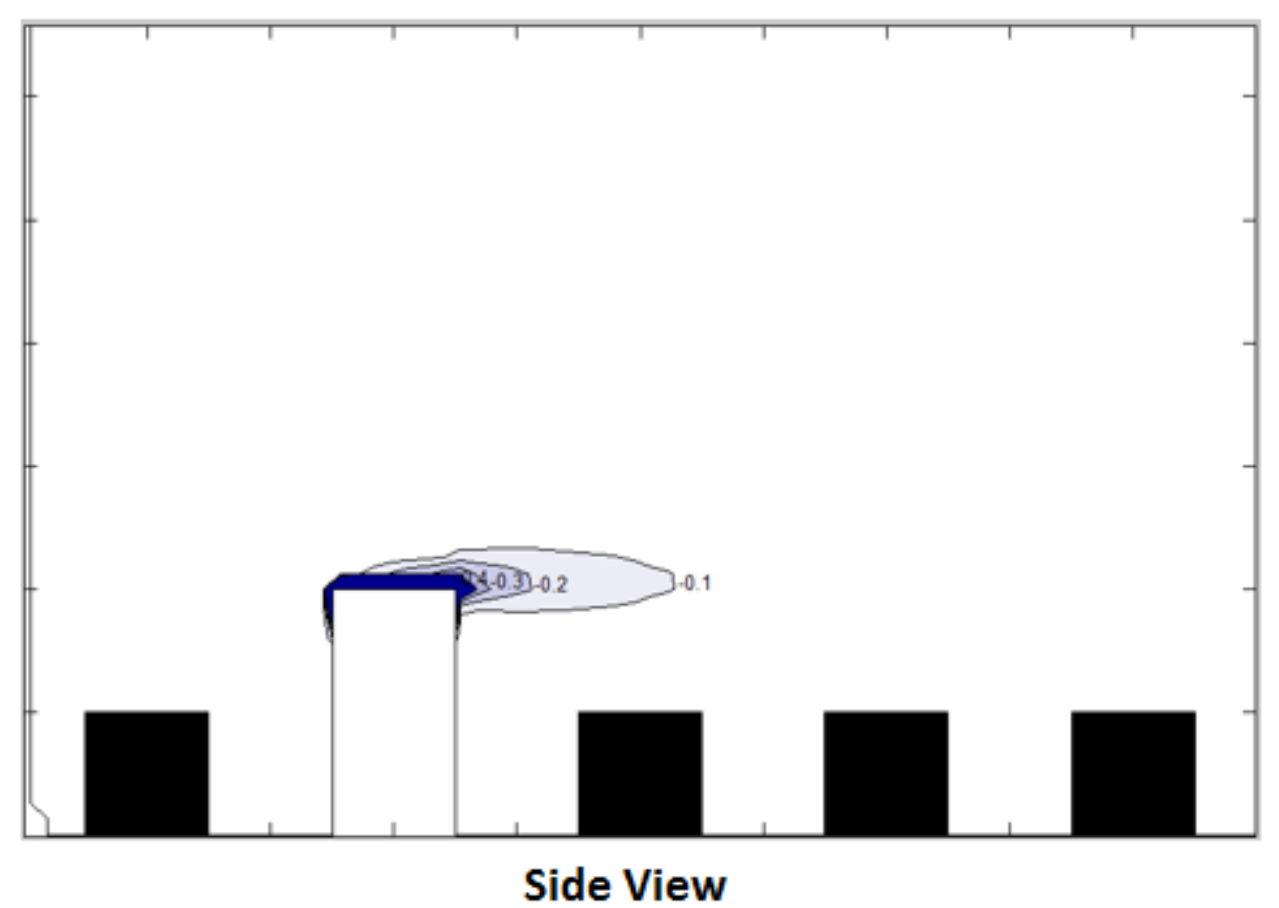

Figure 8: Temperature reductions $\left({ }^{\circ} \mathrm{C}\right)$ for Case 4 single white roof (height 15.2 meters) within array of buildings with uniform height 7.6 meters. 


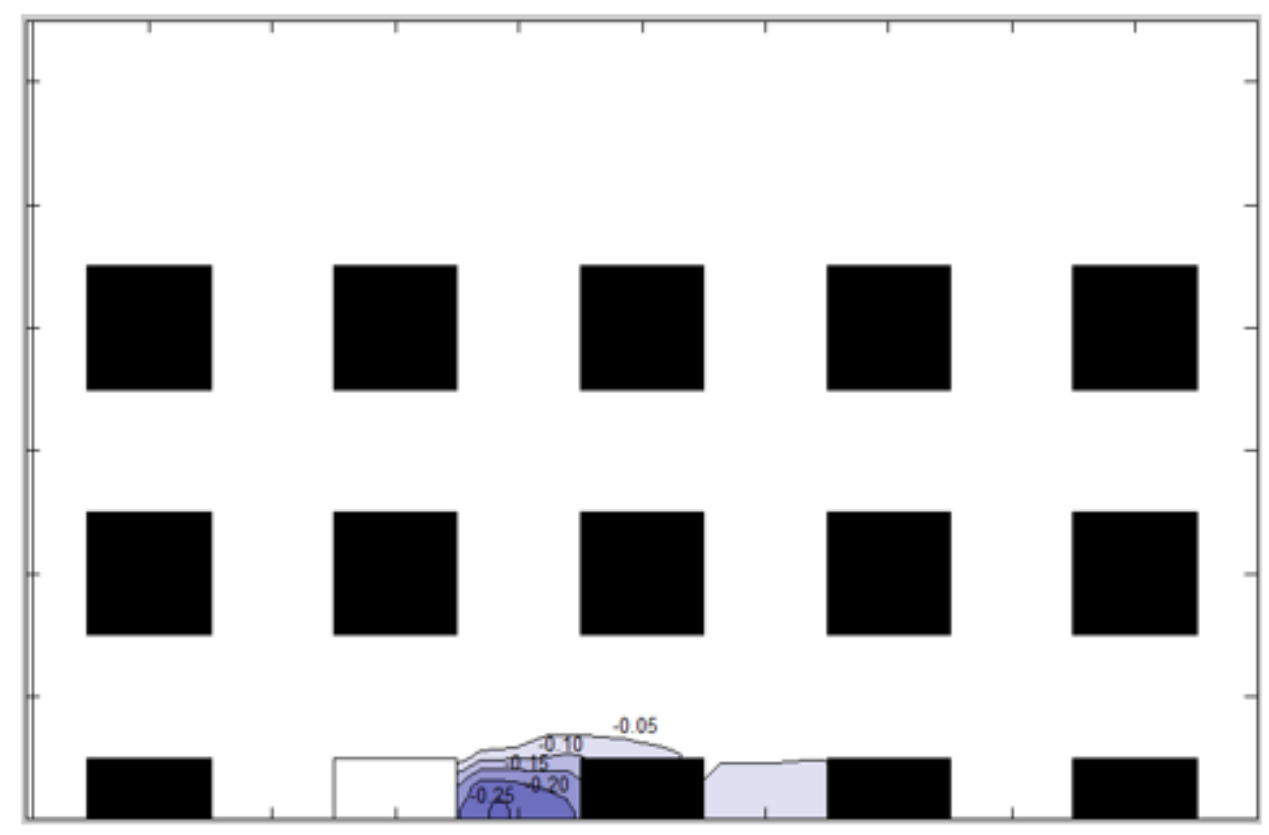

\section{Top View}

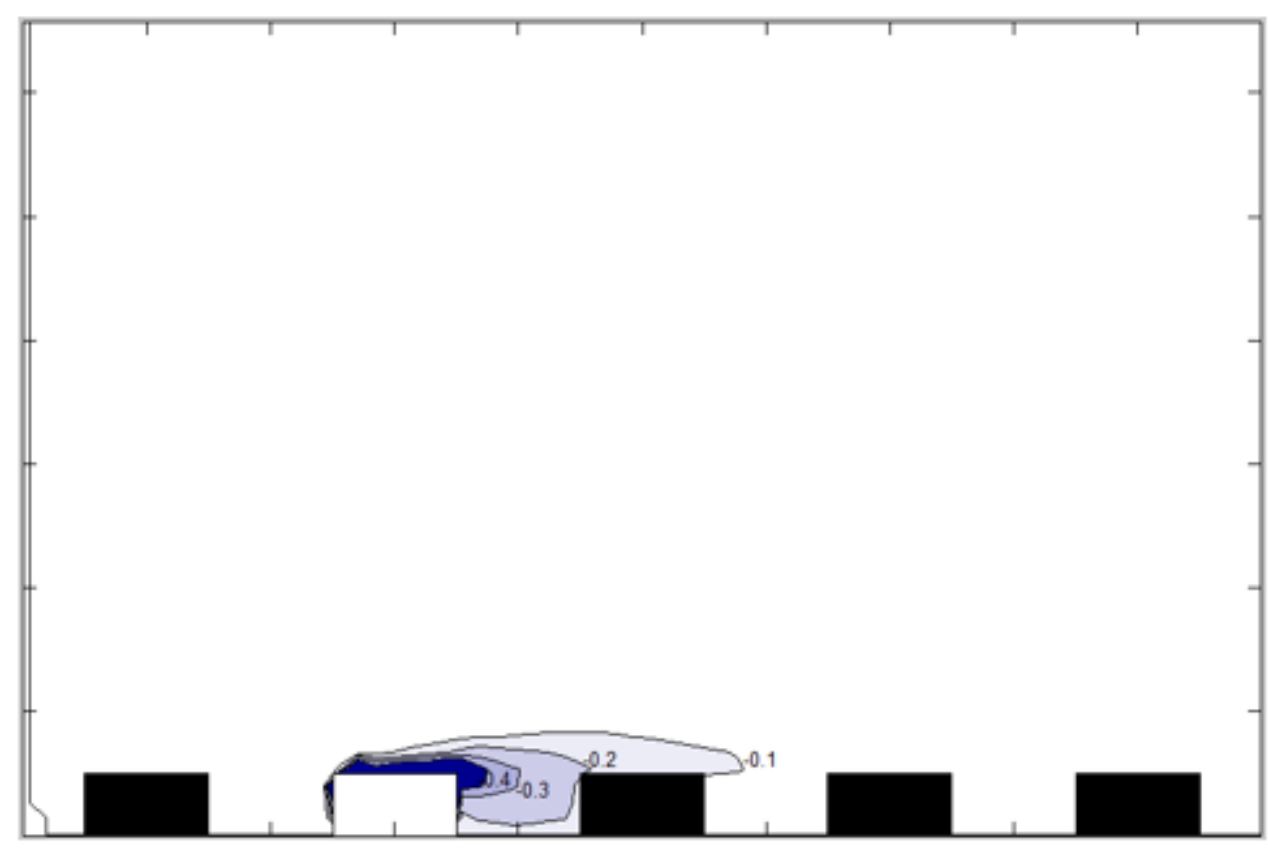

\section{Side View}

Figure 9: Temperature reductions $\left({ }^{\circ} \mathrm{C}\right)$ for Case $5(\mathrm{H} / \mathrm{W}=0.5: 1)$ single white roof (height 3.6 meters) within array of buildings with uniform height 3.6 meters. 


\section{Discussion and Conclusion}

The contour plots (Figures 5-9) indicate differences in the shape and magnitudes of the downwind thermal disturbance caused by a single white roof. The volumetric heat removal (VHR) for cases 1,2 , and 5 (1:1, 2:1, and 0.5:1) for pedestrian and lower heights were approximately equivalent. Volumetric heat removal for case 4 (1:1 except for a single tall white roof) for pedestrian and lower height was negligible while case 3 (1:1 except for a tall building downwind of the white roof) had the greatest effect at the pedestrian and lower height due to the blocking effect of the downwind building. The thermal footprint ratio at $2 \mathrm{~m}$ height clearly shows that case 3 and case 5 are the best choices if the goal is to maximize the extent of cooling at the pedestrian level. This is because the presence of a tall building downwind of the modified roof causes downward motion for the relatively cool air flowing over the modified white roof. In the absence of this variation in building heights the domains with the shortest buildings (Case 5, followed by Case 1 ) show the best performance with respect to $\mathrm{TFR}_{2 \mathrm{~m}}$. At a domainwide level, Case 2 (2:1) appears to perform slightly better than the other cases. This would appear to be a result of the higher elevation of the roof which places it in a region of higher local air velocities (higher convection coefficients) and lower ambient air temperatures. Thus, albedo modification of tall buildings may have the largest cooling effect in the urban atmosphere as a whole. However, if the goal is to have maximum cooling effect at the pedestrian level the modified rooftops should be on relatively short buildings and upwind of taller buildings.

The results of this study emphasize the importance of the vertical structure of cities in assessing the performance of rooftop implementation of urban cooling strategies. Specifically, a white roof is only helpful to pedestrians if the cooler air reaches them and this typically occurs either when (1) the airflow path is deflected/mixed from the airspace of the cool rooftop to the street level and/or (2) when buoyant conditions are strong enough to carry the less-dense cooler air into the canyon. As previously 
noted, the cooling effect at the pedestrian level becomes less noticeable as building heights increase. This indicates that cool roof efficacy for the purpose of pedestrian thermal comfort diminishes with the height of the building. The benefits from the total domain cooling may play a more important role when there are a large number of tall buildings that could take advantage of the cooling of the outdoor climate nearer to the urban canopy.

This study has made several assumptions that limit its broad applicability. The steady state condition is unable to take into account any heat storage within buildings or roads and the constant temperature boundary conditions were used in lieu of an applied heat flux from solar and long wave radiation. The inlet flow-field was only for a single direction and was found by running a flow simulation over a theoretically infinite number of rows of buildings with like-morphology. All of these assumptions effectively forced a solution type in order to demonstrate the usefulness of these methods to evaluate UHI mitigation strategies. Nevertheless, by describing how mitigation strategies may be quantified and compared using the Thermal Footprint Ratio and the Volumetric Heat Removal calculations this study demonstrates that such quantifications are possible as mitigation strategies are put to application within a diverse array of urban environments.

The next step toward quantifying UHI mitigation strategies should take into account the time-dependent effects (diurnal and seasonal) of the basic cool roof cases studied here. This analysis would include energy balances at ground, wall, and roof surfaces instead of assuming a constant temperature taken at the warmest time of the day. Many studies currently focus on summer cooling benefits for cities in the northern hemisphere while ignoring possible winter cooling penalties. By quantifying time averaged values for TFR and DVM seasonally and yearly it would be possible to develop a more complete understanding of the benefits of mitigation strategies. These methods can also be used to investigate 
and compare mitigation from street and rooftop implementation of vegetation, which are also common UHI mitigation strategies [34] [35].

Acknowledgements. This work was supported in part by the Department of Energy under Award Number \#DE-EE0003870 and by NPRP grant \# 5-074-5-015 from the Qatar National Research Fund (a member of Qatar Foundation). The statements made herein are solely the responsibility of the authors. 


\section{References}

[1] UN, "World urbanization prospects: the 2011 revision," United Nations, New York, 2012.

[2] International Energy Agency, "World Energy Outlook 2008," IEA, Paris, 2008.

[3] Y. Zhang, J. Zhang, Y. Zhifeng and S. Li, "Regional differences in the factors that influence China's energy-related carbon emissions, and potential mitigation strategies," Energy Policy, vol. 39, no. 12, pp. 7712-7718, 2011.

[4] L. McCauley, J. Jenkins and P. Quintana-Ascencio, "Isolated Wetlands loss and degradation over two decades in an increasingly urbanized landscape," Wetlands, vol. 33, no. 1, pp. 117-127, 2013.

[5] S. Hajat, M. O'Connor and T. Kosatsky, "Health effects of hot weather: from awareness of risk factors to effective health protection," The Lancet, vol. 375, no. 9717, pp. 856-863, 2010.

[6] S. Hassid, M. Santamouris, N. Papanikolaou, A. Linardi, N. Klitsikas, C. Georgakis and D. N. Assimakopoulos, "The effect of the Athens heat island on air conditioning load," Energy and Buildings, vol. 32, pp. 131-141, 2000.

[7] A. H. Rosenfeld, H. Akbari, S. Bretz, B. L. Fishman, D. M. Kurn, D. Sailor and H. Taha, "Mitigation of urban heat islands: materials, utility programs, updates," Energy and Buildings, vol. 22, pp. 255-265, 1995.

[8] J. Tan, Y. Zheng, X. Tang, C. Guo, L. Li, G. Song, X. Zhen, D. Yuan, A. J. Kalkstein, F. Li and H. Chen, "The urban heat island and its impact on heat waves and human health in Shanghai," International Journal of Biometeorology, vol. 54, pp. 75-84, 2010.

[9] S. Grimmond, "Urbanization and global environmental change: local effects of urban warming," The Geographical Journal, vol. 173, no. 1, pp. 83-88, 2007.

[10] W. Solecki, C. Rosenzweig, L. Parshall, G. Pope, M. Clark, J. Cox and M. Wiencke, "Mitigation of the heat island effect in urban New Jersey," Global Environmental Change Part B: Environmental Hazards, vol. 6, no. 1, pp. 39-49, 2005.

[11] H. Fan and D. Sailor, "Modeling the impacts of anthropogenic heating on the urban climate of Philadelphia: a comparison of implementations in two PBL schemes," Atmospheric Environment, vol. 39, no. 1, pp. 73-84, 2005. 
[12] H. Akbari, R. Levinson and L. Rainer, "Monitoring the energy-use effects of cool roofs on California commercial buildings," Energy and Buildings, vol. 37, pp. 1007-1016, 2005.

[13] H. Takebayashi and M. Moriyama, "Surface heat budget on green roof and high rflection roof for mitigation of urban heat island," Building and Environment, vol. 42, no. 8, pp. 297-2979, 2007.

[14] E. Bozonnet, M. Doya and F. Allard, "Cool roofs impact on building thermal response: A French case study," Energy and Buildings, vol. 43, no. 11, pp. 3006-3012, 2011.

[15] R. Levinson and H. Akbari, "Potential benefits of cool roofs on commercial buildings: conserving energy, saving money, and reducing emission of greenhouse gases and air pollutants," Energy Efficiency, vol. 3, pp. 53-109, 2010.

[16] H. Akbari, M. Pomerants and H. Taha, "Cool surfaces and shade trees to reduce energy use and improve air quality in urban areas," Solar Energy, vol. 70, no. 3, pp. 295-310, 2001.

[17] H. Akbari, S. Menon and A. Rosenfeld, "Global cooling: increasing world-wide urban albedos to offset CO2," Climatic Change, pp. 275-286, 2009.

[18] TRNSYS, A transient system simulator program, Madison: Solar Energy Laboratory, University of Wisconsin.

[19] A. Synnefa, M. Santamouris and H. Akbari, "Estimating the effect of using cool coatings on energy loads and thermal comfort in residential buildings in various climatic conditions," Energy and Buildings, pp. 1167-1174, 2007.

[20] D. Sailor, "Simulated urban climate response to modifications in surface albedo and vegetative cover," Journal of Applied Meteorology and Climatology, vol. 34, no. 7, pp. 1694-1704, 1995.

[21] E. Krayenhoff and J. Voogt, "Impacts of urban albedo increase on local air temperature at dailyannual time scales: Model results and synthesis of previous work," Journal of Applied Meteorology and Climatology, vol. 49, no. 8, pp. 1634-1648, 2010.

[22] A. Synnefa, A. Dandou, M. Santamouris, M. Tombrou and N. Soulakellis, "On the use of cool materials as a heat island mitigation strategy," Journal of Applied Meteorology and Climatology, vol. 47, no. 11, pp. 2846-2856, 2008.

[23] M. Bruse, "ENVI-met 3.0: updated model overview," University of Bochum, 2004. [Online]. Available: www.envi-met.com.

[24] R. Emmanuel and H. Fernando, "Urban heat island in humid and arid climates: role of urban form and thermal properties in Colombo, Sri Lanka and Phoenix, USA," Climate Research, vol. 34, no. 3, pp. 241-251, 2007. 
[25] R. Emmanuel, H. Rosenlund and E. Johansson, "Urban Shading - a design option for the tropics? A study in Colombo, Sri Lanka," International Journal of Climatology, vol. 27, no. 14, pp. 1995-2004, 2007.

[26] S. Saneinejad, P. Moonen and J. Carmeliet, "Comparative assessment of various heat island mitigation measures," Building and Environment, vol. 73, pp. 162-170, 2014.

[27] M. Georgescu, A. Mahalov and M. Moustaoui, "Seasonal hydroclimatic impacts of Sun Corridor expansion," Environmental Research Letters, vol. 7, no. 3, pp. 1-9, 2012.

[28] J. Yang, Z. Wang and K. Kaloush, "Unintended consequences: A research synthesis examining the use of reflective pavements to mitigate the urban heat island effect," Arizona State University, 2013.

[29] S. Patankar, Numerical heat transfer and fluid flow, Washington D.C.: Hemisphere, 1980, pp. 123131.

[30] F. Incropera and D. Dewitt, Fundamentals of Heat and mass Transfer, Jefferson City: John Wiley \& Sons, 2007.

[31] V. Sridhar and R. Elliott, "On the development of a simple downwelling longwave radiation scheme," Agriculatural and Forest Meteorology, vol. 112, no. 3, pp. 237-243, 2002.

[32] National Oceanic \& Atmospheric Administration, "Earth System Research Laboratory Global Monitoring Divsion," [Online]. Available: http://www.esrl.noaa.gov/gmd/grad/surfrad/.

[33] H. Versteeg and W. Malalasekera, An Introduction to Computational Fluid Dynamics: The Finite Volume Method, New York: John Wiley \& Sons Inc, 1996, p. 208.

[34] T. Susca, S. Gaffin and G. Dell'Osso, "Positive effects of vegetation: Urban heat island and green roofs," Environmental Pollution, vol. 159, no. 8-9, pp. 2119-2126, 2011.

[35] J. Declet-Barreto, A. Brazel, C. Martin, W. Chow and S. Harlan, "Creating the park cool island in an inner-city neighborhood: heat mitigation strategy for Phoenix, AZ," Urban Ecosystems, vol. 16, no. 3, pp. 617-635, 2013. 